\title{
ECT in Scotland
}

\author{
Carol Robertson, Chris P. L. Freeman and Grace Fergusson
}

Previous audit of electroconvulsive therapy (ECT) standards has identified deficiencies in service provision. Little national information was avaliable on ECT services in Scottand. Survey questionnaires were sent to all consultants in charge of ECT clinics in Scotland. There was a $100 \%$ response rate. The service proviston varied across Scottand, and in some cases fell bolow Royal College of Psychiatrists' recommendations. There now exists a base of information on services avallable and an ongoing nationat audit system should be considered. Several recommendations hove been made for the future of ECT services in Scotiand and these have been distributed to consultants in charge of clinics.

During discussion in the Scotmeg/Clinical Research and Audit Group (CRAG) into good practice in electroconvulsive therapy (ECT) it became apparent that very little central information was available on the current practice of ECT prescription and delivery within Scotland. Some areas had gathered their own information but there had been no general data collection. As was highlighted in reports by John Pippard (Pippard \& Ellam, 1981; Pippard, 1992), there is wide variation in ECT prescribing practice and in the quality of service provision. The committee (C.R., C.F. and G.F.) decided to initiate a large scale survey of current practice of ECT usage to facilitate future recommendations for good practice within Scotland.

\section{The study}

A questionnaire, designed by the committee and sent to all ECT centres within Scotland, requested information on the facilities provided, staffing levels, training. ECT equipment, anaesthetic equipment, patients treated, treatment techniques and ECT audit. The responsible consultants were sent a covering letter explaining the purpose of the questionnaire and how the information would be used.

A total of 31 questionnaires were sent to NHS facilities, one to the state hospital at Carstairs and one to a private hospital. All questionnaires have been returned. The results are presented for all NHS facilities and separate comment is made on the state hospital and private facilities.

\section{Findings}

\section{ECT facilities}

In keeping with College guidelines (Freeman, 1989), no hospital was administering ECT on open wards. In three hospitals ECT was administered in a side room but the vast majority of the hospitals, $28(90 \%)$, had dedicated ECT suites. The majority of clinics also had a separate preECT waiting room and a recovery area in addition to the ECT treatment room. Fifty-five per cent of the responsible medical officers found these arrangements very satisfactory, $45 \%$ found them satisfactory and none found the arrangements unsatisfactory.

\section{Staffing}

Current guidelines from the College state that sessional time be set aside for the psychiatrist responsible for the ECT clinic. It was therefore disappointing that $84 \%$ of the consultants who responded did not have sessional time avallable for this commitment. This is obviously an area of concern which must be raised nationally and locally. It is presumably a reflection of the lack of time available that no consultants attended every ECT session and the vast majority attended less than one per month. The unsatisfactory nature of a large number of junior staff rotating through ECT clinics was highlighted by Pippard (1992) and recommendations were made that this should not continue. However, in our survey $78 \%$ of ECT was administered by a rotating senior house officer (SHO) or registrar with the numbers on the rota varying from three to 10 , the average number being six (Table 1). In only six of the clinics (19\%) did SHOs and registrars do blocks of treatment sessions which would be a more satisfactory situation.

Table 1. Summary of findings $(n=31)$

\begin{tabular}{lll}
\hline & Yes (\%) & No (\%) \\
\hline Consultant sessional time available & 16 & 84 \\
Juniors administering ECT on large & 78 & 22 \\
rotas & 25 & 75 \\
Obsolete ECT machines used & 42 & 58 \\
Hamilton Cuff method used & \\
$\begin{array}{l}\text { Occasionally } \\
\text { Continued audlt }\end{array}$ & 29 & 71 \\
\hline
\end{tabular}


In $14(45 \%)$ of the clinics nursing staff rotated from the ward to administer ECT, but in addition, $80 \%$ of the clinics had dedicated ECT nurses. In only five clinics (15\%) was an operating department assistant available to the anaesthetist for the purpose of administering ECT. This may become an issue in the future when the Association of Anaesthetists produces new guidelines on ECT administration.

\section{Training}

It was encouraging to find that $90 \%$ of clinics had an ECT Lecture Induction Course for their new junior staff and that in $77 \%$ of cases this included a practical demonstration of ECT administration. In $74 \%$ of clinics new junior doctors had at least one supervised session of ECT administration prior to giving treatment on their own. This leaves $26 \%$ of clinics where SHOs administer their first ECT unsupervised. In only six clinics (19\%) was ongoing refresher training offered, which is unacceptably low and well below the American standards (American Psychiatric Association, 1990) for ECT practice 'privileging'.

However, $24(77 \%)$ of the psychiatrists who responded had attended a recent College ECT Training Course. This high percentage reflects the enthusiasm of local consultants to continue their education regarding ECT administration.

\section{Equipment and monitoring}

The questionnaire asked responsible medical officers to stipulate which ECT machine was used as their main machine and which as their back-up machine. The replies were at times confusing. however, it is obvious that several clinics are using ECT machines which do not meet the recommendations of the College. Six clinics (19\%) still used the Duopulse ECT machine which has long been superseded by a more modern and appropriate device. One clinic had the Siemens Konvulsator machine and one the Ectonus 3, again machines now obsolete.

The Ectron machines were by far the most popular with the largest number of clinics, 13 (42\%), having the Ectonus Series 5 machine, the then recommendation of the College, although this has now been updated (Royal College of Psychiatrists, 1995). This machine has now been superseded by the Ectonus Series 5A (and 5B) and three clinics in Scotland were using the $5 \mathrm{~A}$ machine. Four hospitals used the Neurotronic ECT Machine while another utilised a Thymatron DGx and one a MECTA machine. Therefore very few clinics within Scotland would, at the present time, be able to adequately administer a full regime of stimulus dosing (Sackeim et al, 1987) for every patient using the machines they currently possess.

It was encouraging that $29(94 \%)$ of clinics monitored seizure length routinely. However, this was rarely done using the Hamilton Cuff method (Adderley \& Hamilton, 1953) recommended by the College. Only one clinic does this routinely and $17(58 \%)$ never use the Hamilton Cuff method. Very few clinics used equipment other than simple wall clocks and on occasion stop-watches, with only a minority having access to electroencephalogram (Scott et al, 1989) and electromyogram monitoring.

Few clinics had no policy on restimulation for people who had 'short seizures'. Fifteen clinics (48\%) had a written policy on restimulation and $14(45 \%)$ had a verbal policy. Twenty-four (77\%) of the clinics had arrangements in place for altering the standard setting of their ECT machine throughout a course of ECT, an encouraging adherence to College guidance. but seven (23\%) had absolutely no arrangements for altering the standard setting of the machine throughout the course of ECT. In these clinics an unacceptably low standard of ECT administration was the case.

The anaesthetic equipment used in most clinics was satisfactory and within the present College guidelines. However, only $48 \%$ of clinics had tipping patient trolleys, and their use would be considered good practice (Royal College of Psychiatrists, 1995).

\section{Patients treated}

Twenty-five $(80 \%)$ of the clinics provided treatment on two days a week, the remainder on three or four days per week. The most popular days were Tuesday and Friday. When questioned regarding the availability of additional emergency week-day ECT sessions, $13(42 \%)$ of the clinics said that this would be easily available while $16(52 \%)$ found they could administer ECT at these times with 'some difficulty'. In two clinics additional ECT sessions were not available. With regard to additional weekend ECT sessions, only eight $(26 \%)$ thought this would be easily available and in six clinics this service was not available.

All clinics kept ECT record forms for every patient and $23(74 \%)$ also had separate ECT recording sheets. Some clinics used additional anaesthetic log books. In two clinics computerised records were kept. If a national information gathering system is to be instituted, a more uniform method of data collection will have to be devised.

From the approximate data available the total number of patients treated in Scotland per year was 2513, these patients receiving about 15119 ECT treatments. The total population of 
5186000 gives an average of 2.9 treatments per 1000 population. This figure is lower than those provided by Pippard (1992) and to the figures available from Ireland (Latey \& Fahy, 1988). although direct comparison must be cautious given very marked regional variations and decrease in usage of ECT over time.

The majority of ECT clinics in Scotland would appear to be on one hospital site with only four clinics providing services to multiple hospital sites. Only in five ECT centres were patients having to travel. The clinicians estimated that 47 patients per year would have to travel from 5 to 20 miles, averaging out at 10 miles per patient. Out-patient ECT is very rarely used in Scotland with only one clinic administering it to more than $25 \%$ of their patients. Similarly unilateral treatment is rarely used, the majority of ECT being administered bilaterally.

Specific questions were asked regarding ECT administration to young people given the recent press and College concern. No clinics could recall ECT being given in the past 10 years to people between 0 and 13 years. From 13 to 17 a total of six patients in 10 years could be recalled. In most cases these people were 15 and 16 years old rather than 13-14.

Audit

Only nine (29\%) of the clinics had ongoing audit of their ECT practice (Table 1). This falls short of the guidelines of the College and the recommendation of Pippard (1992).

\section{State hospital - Carstairs}

The situation at the state hospital is different from that at other NHS hospitals given the special population they deal with. ECT is used infrequently and does not necessitate the formal services routinely available in other hospitals. The facilities available are currently being reviewed but it appears that these arrangements are satisfactory and in line with College guidelines.

\section{Private ECT facilities}

The one response from a private facility suggests that little ECT is administered in this area in Scotland. The facilities differ from most NHS hospitals, with the treatment being administered in the patient's own room by the responsible consultant. Standards of equipment and monitoring appear acceptable.

\section{Comment}

This questionnaire has provided information not previously available, and has demonstrated the widespread use of ECT in Scotland. The response rate was $100 \%$. The results indicate that service provision as a whole in Scotland is acceptable though several areas have been highlighted as requiring attention. As with all self-reported surveys it is possible that the answers do not precisely represent the true picture. The actual situation in some clinics may be less favourable than reported and only by unannounced personal visits would these discrepancies be highlighted.

The apparently low level of usage of ECT in Scotland may be genuine but as these results relied on self-reports rather than ongoing audit the figures must be taken as approximate. However, it is probable that the usage of ECT is declining and the figures from this audit may reflect the changes since the previous audit. The specific areas highlighted by the results were similar to those highlighted by earlier surveys in England (Pippard \& Ellam, 1981; Pippard, 1992).

Several recommendations arise from the findings: consultant staff should have more sessional time available to allow supervision of ECT services; the use of junior doctors working on large rotas to administer ECT is to be discouraged: continuous training in ECT theory and techniques should be more widely available; the use of obsolete ECT machines is unacceptable; use of the Hamilton Cuff method for monitoring seizure duration is to be encouraged; a local policy on restimulation should be available: continued audit of ECT is to be encouraged; and a national system of collecting figures on the use of ECT should be established.

\section{Acknowledgements}

The committee thank the staff who responded to our questionnaire and provided this very valuable and previously uncollected information.

\section{References}

ADDERLEY, D. J. \& HAMILTON, M. (1953) Use of succinylcholine in ECT. British Medical Joumal, is 195-197.

AMERICAN PSYChIATRIC AsSOCLATION (1990) Task Force on ECT - The Practice of ECT. Washington. DC: American Psychiatric Press.

Freeman. C. P. (1989) The Practical Administration of Electroconvulsive Therapy (ECT). ECT Sub-Committee of the Royal College of Psychiatrists. London: Gaskell.

LATEY, R. H. \& FAHY, T. J. (1988) Some influences on regional variation in frequency of prescription of ECT. British Journal of Psychiatry. 182, 196-200.

PIPPARD. J. (1992) Audit of ECT in Two National Health service reglons. British Joumal of Psychiatry. 160. 621-637.

- \& EluM. L. (1981) Electroconuulsive Treatment in Great Britain. London: Gaskell.

Royal College OF PSYChIATRISTS (1995) ECT-1995. London: Royal College of Psychiatrists. 
Sackeim, H., Decina, P., Prohovin, I., et al (1987) Seizure threshold in electroconvulstve therapy. Effects of sex. age, electrode placement and number of treatments. Archives of General Psychiatry, 44, 355-360.

ScotT, A. I. F.. Shering, A. \& Dykes, S. (1989) Would monitoring by EEG improve the practice of ECT? British Journal of Psychiatry. 164, 853-857.

*Carol Robertson, Senior Registrar, Royal Cornhill Hospital, Aberdeen AB9 2ZH; Chris P. L. Freeman.
Consultant Psychiatrist and Honorary Senior Lecturer, Royal Edinburgh Hospital, Morningside Terrace, Edinburgh EH10 5HF; and Grace Fergusson, Associate Specialist, Argyll and Bute Hospital, Lochgilphead, Argyll PA31 8LD

*Correspondence

\section{The ECT Handbook}

\section{The Second Report of the Royal College of Psychiatrists' Special Committee on ECT Edited by C. P. Freeman}

This report is a practical set of guidelines for psychiatrists who will be prescribing or administering ECT. It covers clinical guidelines, administration of ECT, the law and consent to treatment. Nursing guidelines, a review of ECT machines and a checklist for good practice are also included. Appendices covering new developments will regularly be produced and distributed as inserts to this volume. There is a separate teaching video available to complement the text, priced $£ 30.00$.

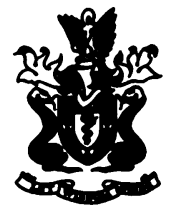

— £14.99 — 168pp. — 1995 — ISBN 0902241834

Available from the Publications Department, Royal College of Psychiatrists, 17 Belgrave Square, London SW1X 8PG (Tel. 0171-235 2351 extension 146) 